\title{
Development of a Novel Fluorescence Assay Based on the Use of the Thrombin-Binding Aptamer for the Detection of $0^{6}$-Alkylguanine-DNA Alkyltransferase Activity
}

\author{
Maria Tintoré, ${ }^{1}$ Anna Aviñó, ${ }^{1}$ Federico M. Ruiz, ${ }^{2}$ Ramón Eritja, ${ }^{1}$ and Carme Fàbrega ${ }^{1}$ \\ ${ }^{1}$ Institute for Research in Biomedicine (IRB Barcelona) IQAC-CSIC, CIBER-BBN Networking Centre on Bioengineering Biomaterials \\ and Nanomedicine, Cluster Building, Baldiri i Reixac 10, 08028 Barcelona, Spain \\ ${ }^{2}$ Chemical and Physical Biology CIB (CSIC), Ramiro de Maeztu 9, 28040 Madrid, Spain
}

Correspondence should be addressed to Carme Fàbrega, carme.fabrega@irbbarcelona.org

Received 11 June 2010; Accepted 17 July 2010

Academic Editor: Ashis Basu

Copyright ( $) 2010$ Maria Tintoré et al. This is an open access article distributed under the Creative Commons Attribution License, which permits unrestricted use, distribution, and reproduction in any medium, provided the original work is properly cited.

\begin{abstract}
Human $\mathrm{O}^{6}$-alkylguanine-DNA alkyltransferase (hAGT) is a DNA repair protein that reverses the effects of alkylating agents by removing DNA adducts from the $\mathrm{O}^{6}$ position of guanine. Here, we developed a real-time fluorescence hAGT activity assay that is based on the detection of conformational changes of the thrombin-binding aptamer (TBA). The quadruplex structure of TBA is disrupted when a central guanine is replaced by an $\mathrm{O}^{6}$-methyl-guanine. The sequence also contains a fluorophore (fluorescein) and a quencher (dabsyl) attached to the opposite ends. In the unfolded structure, the fluorophore and the quencher are separated. When hAGT removes the methyl group from the central guanine of TBA, it folds back immediately into its quadruplex structure. Consequently, the fluorophore and the quencher come into close proximity, thereby resulting in decreased fluorescence intensity. Here, we developed a new method to quantify the hAGT without using radioactivity. This new fluorescence resonance energy transfer assay has been designed to detect the conformational change of TBA that is induced by the removal of the $\mathrm{O}^{6}$-methyl group.
\end{abstract}

\section{Introduction}

Alkylating agents are chemotherapeutic anticancer drugs that produce their cytotoxic effect by generating adducts at multiple sites in DNA [1]. A subset of alkylating agents, which includes nitrosoureas and temozolamide, have a preference for alkylating guanine at the $\mathrm{O}^{6}$ position, which is the most relevant in terms of mutagenesis and carcinogenesis [2-9]. In particular, 1,3-bis-(2-chloroethyl)-1-nitrosourea (BCNU) attacks initially at the $\mathrm{O}^{6}$ guanine position, causing its rearrangement in a cyclic intermediate thus giving rise to $\mathrm{N}^{1}, \mathrm{O}^{6}$-ethanoguanine [10]. Finally, a cross-link with the opposite cytosine is formed, and, as a consequence, DNA replication is blocked, producing G2/M arrest [11]. In addition to the well-known side effects and limitations of chemotherapeutic agents, these substances also present problems of acquired tumor resistance. In particular, the DNA-repair human $\mathrm{O}^{6}$-alkylguanine DNA alkyltransferase
(hAGT or MGMT) is responsible for removing alkyl adducts from the $\mathrm{O}^{6}$ position of guanines, thereby blocking the cytotoxic effects of the alkylating agents and making a crucial contribution to the resistance mechanism [12-14]. It is well established that tumor cells show greater expression of this protein than healthy cells. Thus, this increased expression appears to be predictive of a poor response to chemotherapeutic drugs. This effect has been observed in a large number of cancers, ranging from colon cancer, lung tumors, breast cancer, pancreatic tumors, non-Hodgkin's lymphoma, myeloma, and glioblastoma multiforme, among others [1517]. In addition methylation of the hAGT promoter and consequently the complete depletion of hAGT, it has been associated with longer survival in patients with gliomas undergoing combined radiation-chemotherapy treatment $[18,19]$. Therefore, pharmacological inhibition of hAGT has the potential to enhance the cytotoxicity of a diverse range of anticancer agents [20]. 
hAGT is a $22-\mathrm{kDa}$ (207 AA) DNA-binding protein that contains a highly conserved internal cysteine, which acts as the acceptor site for alkyl groups. The S-alkyl-Cys formed is not regenerated and the protein, which behaves as a suicidal enzyme, inactivates itself in the dealkylation process $[21,22]$. This single turnover of hAGT renders it vulnerable to inactivation. On the basis of this observation, intense research effort has been devoted to the identification of small molecules capable of inhibiting hAGT activity and significantly enhancing the cytotoxic effect of BCNU in prostate, breast, colon, and lung tumor cells [20].

Several methods are available to characterize the mechanism of action of hAGT and its activity. Moreover, they also have the capacity to evaluate the capacity of small molecules to inhibit hAGT. Most of these methods are based on radioactivity assays while others are based on multiplestep enzymatic reactions [23-26].

G-quadruplexes are a family of four-stranded DNA structures stabilized by the stacking of guanine tetrads, in which four planar guanines form a cyclic array of hydrogen bonds [27]. These G-rich regions are connected by lateral, central, or diagonal loops of diverse sizes and composition that form base-pairing alignments, which in turn stack with the terminal G-tetrads, thus further stabilizing Gquadruplex structures [28]. Another key element in Gquadruplex formation is the presence of monovalent cations, which stabilize the negative electrostatic potential created by the guanine $\mathrm{O}^{6}$ oxygen atoms within the quadruplex core $[29,30]$. However, most divalent cations have the capacity to induce the dissociation of G-quadruplex structures [31]. Finally, modifications in the base composition of the tetrads are poorly tolerated by these structures. As an example, inosine [32] and $\mathrm{O}^{6}$-methylguanine [33], both nonnatural bases can form a smaller number of hydrogen bonds and thus destabilize the G-quadruplex.

Given the potential relevance of hAGT as a prognostic marker of cancer and as a therapeutic target, and that its substrate $\mathrm{O}^{6}$-methylguanine disrupts the formation of G-quadruplex structures [33], here, we developed a new fluorescence activity assay for hAGT. For this purpose, we selected the thrombin-binding aptamer (TBA) as our Gquadruplex model. TBA is a well-known 15 mer that adopts a chair-like structure consisting of two G-tetrads connected by two lateral TT loops and a central TGT loop [34]. The modification of its sequence in positions 5 or 6 by replacing a guanine of the tetrad for an $\mathrm{O}^{6}$-methylguanine disrupts folding, leaving it in an extended conformation. Giving that the two conformations bring the two ends of TBA together take them further apart, our working hypothesis was that the incorporation of fluorescence probes results in a measurable change in intensity. The final aim of this fluorescence assay was to measure the DNA repair activity of hAGT and thus facilitate the search for new and more potent inhibitors which enhance chemotherapeutic drugs. Although several methods have been described to quantify hAGT activity [2326], none of them use the conformational change of Gquadruplex for this purpose. Here, we describe the development of a straightforward, rapid, one-step fluorescence resonance energy transfer (FRET) assay.

\section{Materials and Methods}

2.1. Chemicals. 5'-Fluorescein CE phosphoramidite (6FAM), 3'-Dabsyl CPG, $\mathrm{O}^{6}$-methylguanine $\left(\mathrm{O}^{6}-\mathrm{MeG}\right)$ and $\mathrm{G}^{\mathrm{dmf}}$ phosphoramidites were purchased from Link technologies (UK) and Glen Research (USA). $\mathrm{O}^{6}$-methylguanine was protected with the isobutyryl group [35]. Standard phosphoramidites and ancillary reagents were purchased from Applied Biosystems (Europe).

The matrices for MALDI-TOF experiments were $2^{\prime}, 4^{\prime}, 6^{\prime}$ trihydroxiacetophenone monohydrate (THAP) and ammonium citrate dibasic.

Solvents for chromatographic analysis were prepared using triethylamine, acetic acid, and acetonitrile as mobile phase. All other chemicals were of analytical reagent grade and were used as supplied. Ultrapure water (Millipore, USA) was used in all experiments.

2.2. Instrumentation. Semipreparative reverse phase (RP) HPLC was performed on a Waters chromatography system using Nucleosil semipreparative $120 \mathrm{C} 18(250 \times 8 \mathrm{~mm})$ columns. Analytical RP-HPLC was performed using an XBridge OST C18 $2.5 \mu \mathrm{m}$ column and a Nucleosil Analytical column $120 \mathrm{C} 18(250 \times 4 \mathrm{~mm})$. Oligonucleotides were detected by UV absorption at $260 \mathrm{~nm}$. Mass spectra were recorded on a MALDI Voyager $\mathrm{DE}^{\mathrm{TM}} \mathrm{RP}$ time-of-flight (TOF) spectrometer (Applied Biosystems, USA) with a nitrogen laser at $337 \mathrm{~nm}$ using a 3-ns pulse. Fluorometric measurements were performed on a spectrofluorometer multidetection microplate reader Biotek FL $\times 800$ and a Jasco FP6200. Molecular absorption spectra between 220 and $550 \mathrm{~nm}$ were recorded with a Jasco V650 spectrophotometer. The temperature was controlled with a Jasco ETC $272 \mathrm{~T}$ Peltier device. Hellma quartz cuvettes $(0.5$ and $1.0 \mathrm{~cm}$ path length, 500 or $1000 \mu \mathrm{L}$ volume) were used.

2.3. Oligonucleotide Synthesis. Oligonucleotide sequences (shown in Table 1) were synthesized on an ABI 3400 DNA Synthesizer (Applied Biosystems, USA) using a 200nmol scale synthesis and following the standard protocols. We used dimethylformamidino-protected guanine $\mathrm{G}^{\mathrm{dmf}}$ phosphoramidite for all the syntheses. $5^{\prime}$-Fluorescein CE phosphoramidite (6-FAM), $\mathrm{O}^{6}$-methylguanine $\left(\mathrm{O}^{6}-\mathrm{MeG}\right)$ and $\mathrm{G}^{\mathrm{dmf}}$ phosphoramidites were from commercial sources. The isobutyryl group was used to protect the amino group of $\mathrm{O}^{6}-\mathrm{MeG}$ [35]. The quencher group was introduced at the $3^{\prime}$ end using the controlled pore glass functionalized with a $3^{\prime}$-Dabsyl derivative CPG. $\mathrm{O}^{6}-\mathrm{MeG}$-containing oligonucleotides were deblocked using concentrated aqueous ammonia overnight at room temperature following the manufacturer's instructions. The resulting products were desalted by Sephadex G-25 (NAP-10, GE Healtcare, USA) and purified by reversed-phase HPLC using Nucleosil columns. The yields and purities obtained for the products were around $85 \%$ for $5-\mathrm{O}^{6}-\mathrm{MeG}-\mathrm{TBA}$ and $6-\mathrm{O}^{6}-\mathrm{MeG}-\mathrm{TBA}$, and $>98 \%$ for the rest of the sequences. The length and homogeneity of the oligonucleotides were checked by MALDI-TOF. 
TABLE 1: Sequences of TBA oligonucleotide derivatives used in the development of the hAGT fluorescence assay. ${ }^{\text {Me }} \mathbf{G}$ represents $\mathrm{O}^{6}$ methylguanine. $\mathrm{MB}$ represents the fluorophore group (FAM), labelled in the $5^{\prime}$ end, and the quencher group (Dabsyl), labelled in the $3^{\prime}$ end of the sequence.

\begin{tabular}{|c|c|}
\hline Abbreviation & Sequence \\
\hline TBA & $5^{\prime}$-GGT TGG TGT GGT TGG-3' \\
\hline 5-O $-\mathrm{MeG}-\mathrm{TBA}$ & $5^{\prime}$-GGT T ${ }^{\mathrm{Me}}$ GG TGT GGT TGG-3' \\
\hline $6-\mathrm{O}^{6}-\mathrm{MeG}-\mathrm{TBA}$ & $5^{\prime}$-GGT TG ${ }^{\text {Me }}$ GTGT GGT TGG-3' \\
\hline C-TBA & $5^{\prime}$-CCA ACC ACA CCA ACC-3' \\
\hline MB-TBA & 5'-FAM-GGT TGG TGT GGT TGG-Dabsyl-3' \\
\hline MB-5-O'-MeG-TBA & $5^{\prime}$-FAM-GGT T ${ }^{\text {Me }}$ GG TGT GGT TGG- Dabsyl-3' \\
\hline MB-6-O'- $-\mathrm{MeG}-\mathrm{TBA}$ & $5^{\prime}$-FAM-GGT TG ${ }^{\text {Me }}$ G TGT GGT TGG- Dabsyl-3' \\
\hline 3-HР-TBA & $5^{\prime}$-A CCT TTT GGT TGG TGT GGT TGG-3' \\
\hline 6-HP-TBA & 5'-C CAA CCT TTT GGT TGG TGT GGT TGG-3' \\
\hline 9-HP-TBA & $5^{\prime}$-A CAC CAA CCT TTT GGT TGG TGT GGT TGG-3' \\
\hline
\end{tabular}

5-O'-MeG-TBA $[\mathrm{M}]=4731.7$ (expected 4737.8), 6-0 $\mathbf{O}^{6}$ MeG-TBA [M] = 4729.9 (expected 4737.8), MB-5-O'6-MeGTBA $[\mathrm{M}]=5828.49\left(\right.$ expected 5826.0), MB-6-O ${ }^{6}-\mathbf{M e G}^{-T B A}$ $[\mathrm{M}]=5826.80($ expected 5826.0).

The DNA-strand concentration was determined by absorbance measurements $(260 \mathrm{~nm})$ by calculating extinction coefficients. Oligonucleotide samples were kept at $4^{\circ} \mathrm{C}$ until further use. Double-stranded $\mathrm{O}^{6}-\mathrm{MeG}-\mathrm{TBA}$ was formed by annealing equimolar concentrations of complementary oligonucleotide strands at $72^{\circ} \mathrm{C}$ for $5 \mathrm{~min}$ and then allowed to slowly cool to room temperature.

2.4. Melting Temperature Studies. Melting curves were measured by monitoring the absorbance hyperchromicity at 295 and $495 \mathrm{~nm}$ in a JASCO V650 spectrophotometer equipped with a Peltier temperature-controlling unit. UV/Vis absorption spectra were recorded at $1^{\circ} \mathrm{C} / \mathrm{min}$ intervals, with a 1 min equilibration time at each temperature; the sample was heated over the range $20-80^{\circ} \mathrm{C}$. The buffer solutions used were $10 \mathrm{mM}$ sodium cacodylate $\mathrm{pH} 7.0$ and $100 \mathrm{mM} \mathrm{KCl}$. Sample concentration was around $4 \mu \mathrm{M}$. Each sample was allowed to equilibrate at the initial temperature without any external control of temperature for 5 min before the melting experiment began. The melting temperatures ( $\mathrm{Tm})$ are the average value of at least one pair of Tm experiments.

2.5. CD Spectra. Samples were prepared as described for the melting experiments by UV spectroscopy. Measurements were conducted in $10 \mathrm{mM}$ sodium cacodylate $\mathrm{pH} 7.0$ and $100 \mathrm{mM} \mathrm{KCl}$. Sample concentration was between $1-4 \mu \mathrm{M}$. The CD spectra were recorded on a Jasco J-810 spectropolarimeter attached to a Julabo F/25HD circulating water bath in $1 \mathrm{~cm}$ path-length quartz cylindrical cells. Spectra were recorded at room temperature using a $100 \mathrm{~nm} / \mathrm{min}$ scan rate, a spectral band width of $1 \mathrm{~nm}$ and a time constant of $4 \mathrm{~s}$. All the spectra were corrected with the buffer blank and plotted using Origin software.

2.6. Human Recombinant hAGT Protein. Full-length hAGT was overexpressed and purified as previously described [36].
Briefly, hAGT protein cloned in the pet-21a $(+)$ (Novagen) vector was expressed in the $E$. coli strain Rosetta. Once the culture reached an $\mathrm{OD}_{600}$ value of 0.98 , hAGT was induced by adding $1 \mathrm{mM}$ IPTG (Sigma) and left for $4 \mathrm{~h}$ at $30^{\circ} \mathrm{C}$. The pellet from a 1-L culture was disrupted by sonication and centrifuged. The supernatant was filtered, loaded into a HiTrap FF column (GE Healthcare) with buffer $350 \mathrm{mM}$ $\mathrm{NaCl}, 20 \mathrm{mM}$ Tris $\mathrm{pH}$ 8, $20 \mathrm{mM}$ imidazole, and $1 \mathrm{mM} \mathrm{BME}$, and then eluted with an imidazole (Fluka) gradient up to $500 \mathrm{mM}$ in the same buffer. Finally, the protein was loaded into a Superdex 75 16/60 column (GE Healthcare) with the following buffer: $200 \mathrm{mM} \mathrm{NaCl}$ (Merck), $20 \mathrm{mM}$ Tris $\mathrm{pH} 8.0$ (Merck), 10 mM DTT (Sigma) and 0.1 mM EDTA (Sigma). The protein was concentrated to $2 \mathrm{mg} / \mathrm{mL}$ in this buffer and kept at $-20^{\circ} \mathrm{C}$ in the presence of $40 \%$ glycerol. The same protocol was used for the purification of the inactive mutant hAGT-C145S, cloned in the pet-28a (+) vector (Novagen), and expressed in the E. coli strain BL21.

2.7. HPLC hAGT Assay. Assays were conducted using double-stranded 5- $\mathrm{O}^{6}-\mathrm{MeG}$ and 6- $\mathrm{O}^{6}-\mathrm{MeG}$ TBA paired with TBA complementary sequence or using single-stranded 5$\mathrm{O}^{6}-\mathrm{MeG}$ and $6-\mathrm{O}^{6}-\mathrm{MeG}$ TBA.

In order to measure the dealkylation of $\mathrm{O}^{6}-\mathrm{MeG}, 50 \mathrm{pmol}$ of the $\mathrm{O}^{6}$-MeG-TBA substrates were incubated with a range of concentration of hAGT $(16 \mathrm{nM}$ to $1.6 \mu \mathrm{M})$ to a final volume of $120 \mu \mathrm{L}$ in a reaction buffer $(200 \mathrm{mM} \mathrm{NaCl}$, $50 \mathrm{mM}$ Tris pH 8.0, $1 \mathrm{mM}$ DTT, and $5 \mathrm{mM}$ EDTA). Several incubation times were tested $(30,60,90,120,360$, and 1440 $\min )$ at $37^{\circ} \mathrm{C}$ and the reaction was stopped by heating the samples at $72^{\circ} \mathrm{C}$ for $5 \mathrm{~min}$. The reaction products were analyzed by HPLC on a Nucleosil analytical column at $60^{\circ} \mathrm{C}$ or room temperature, depending on the substrates used in the experiment (double- or single-stranded TBA). The HPLC flow rate was $1 \mathrm{~mL} / \mathrm{min}$, and a gradient of $10 \%-40 \%$ acetonitrile for $20 \mathrm{~min}$ was used.

2.8. Fluorescence Assay for hAGT Activity. The fluorescence assay was performed in a multidetection microplate reader biotek FLx800 in optical 96-well Optical btm reaction plates 


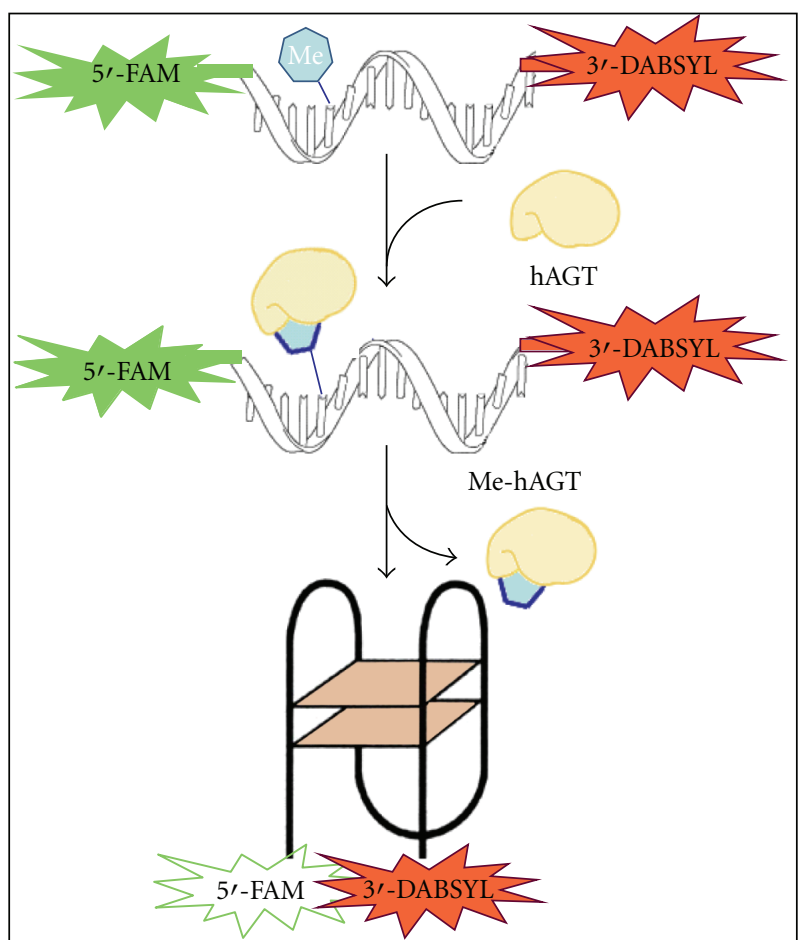

FIGURE 1: Scheme of fluorescence-based hAGT assay. The substrate is the thrombin-binding aptamer modified by an $\mathrm{O}^{6}$ methylguanine $(\mathrm{Me})$ in extended conformation, with a fluorophore and quencher in the opposite ends of the sequence. The refold of the G-quadruplex structure of TBA is dependent on the removal of the methyl adduct by alkyl-guanine-DNA- $\mathrm{O}^{6}$-alkyltransferase (hAGT). This repair moves the quencher and the fluorophore molecules in close proximity and blocks fluorescence.

(Nunc, USA). Full-length hAGT recombinant protein (207 amino acids) was used for the assay and the hAGT-C145S inactive mutant was used as a negative control. The reaction was performed in a total volume of $50 \mu \mathrm{L}$ in each well, incubating increasing concentrations of hAGT $(5,10,20$, $40,60$, and $80 \mathrm{nM})$ enzyme in reaction buffer $(200 \mathrm{mM}$ $\mathrm{NaCl}, 50 \mathrm{mM}$ Tris $\mathrm{pH} 8.0,1 \mathrm{mM}$ DTT, $5 \mathrm{mM}$ EDTA, and $20 \mathrm{mM} \mathrm{KCl}$ ). The assay of hAGT was then initiated by the addition of $5 \mu \mathrm{L}$ of different concentrations $(5,10,25$, and $50 \mathrm{nM}$ ) of fluorescently labelled MB-O ${ }^{6}-\mathrm{MeG}-\mathrm{TBA}$ substrate and this solution was then placed in a microplate reader system. Fluorescence was measured every minute for $20 \mathrm{~min}$ or $40 \mathrm{~min}$ at excitation and emission wavelengths of 485 and $535 \mathrm{~nm}$, respectively. Averages over three readings were taken for each condition tested. Each experiment was performed in triplicate.

\section{Results and Discussion}

The aim of this study was to develop a real-time hAGT activity assay based on the detection of differences between extended and folded conformations of TBA. Our working hypothesis was that the quadruplex structure of TBA is

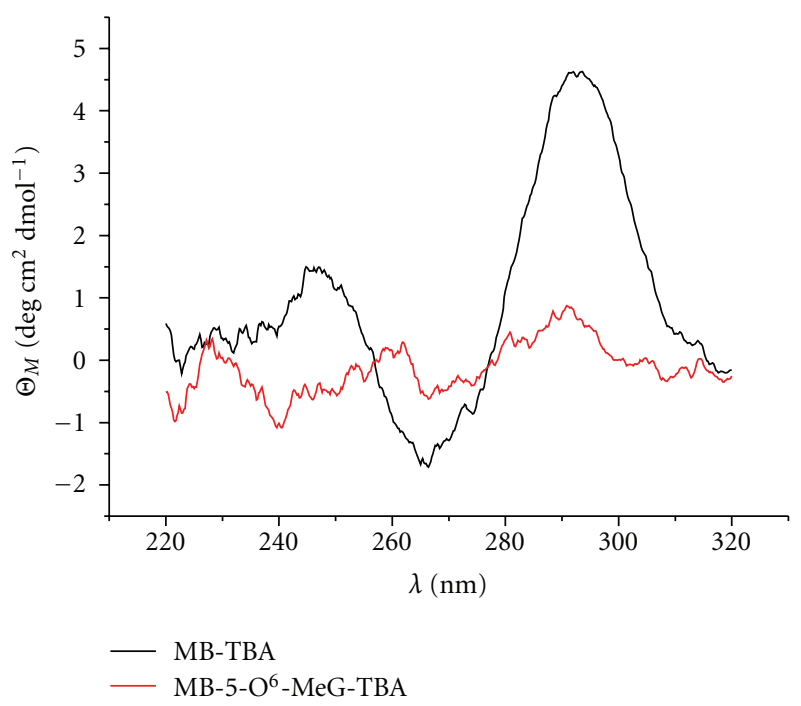

Figure 2: CD spectra of MB-TBA and MB-5-O ${ }^{6}-\mathrm{MeG}-\mathrm{TBA}$ at $25^{\circ} \mathrm{C}$. Buffer conditions: $10 \mathrm{mM}$ sodium cacodylate $\mathrm{pH} 7.0$ and $100 \mathrm{mM} \mathrm{KCl}$, sample concentration $1 \mu \mathrm{M}$.

disrupted when a central guanine is replaced by an $\mathrm{O}^{6}$ methylguanine. The TBA sequence also contains a fluorophore and a quencher group attached to $5^{\prime}$ or $3^{\prime}$ end, respectively. In the presence of $\mathrm{O}^{6}$-methylguanine, methylated TBA unfolds and the fluorophore and the quencher become physically separated beyond the Förster distance. When the repair protein hAGT is added to the methylated aptamer, the enzyme removes the methyl group from the mutated guanine, thus allowing TBA to fold back into its chair-like conformation. As a result, the quencher comes closer to the fluorophore and blocks its fluorescence, as illustrated in Figure 1. This loss of fluorescence is quantified as a direct measurement of hAGT activity.

3.1. Synthesis of Modified G-Quadruplex Sequences. The Gquadruplex sequences used in this study are shown in Table 1. Oligonucleotide synthesis was performed by the solid-phase 2'-cyanoethyl-phosphoramidite method [37]. Ammonia treatment was performed at room temperature overnight to minimize decomposition of $\mathrm{O}^{6}$-methylguanine. For the same reason, the dimethylformamidino group was selected for the protection of $2^{\prime}$-deoxyguanosine [38]. The sequences were characterized by HPLC and mass spectrometry, which provided the expected molecular weights. The yields of the isolated molecular beacon oligonucleotides after HPLC purification and desalting were in the range of those obtained for unmodified oligonucleotides.

3.2. Thermal Stability of Methylguanine-Modified TBA. In order to induce the unfolding of the quadruplex structure of TBA, we introduced an $\mathrm{O}^{6}$-methyl-guanine at position 5 or 6 of TBA. Melting curves of the modified sequences were performed by UV spectroscopy and compared with the unmodified sequence. These experiments were carried 


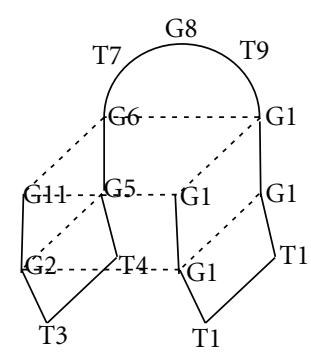

(a)

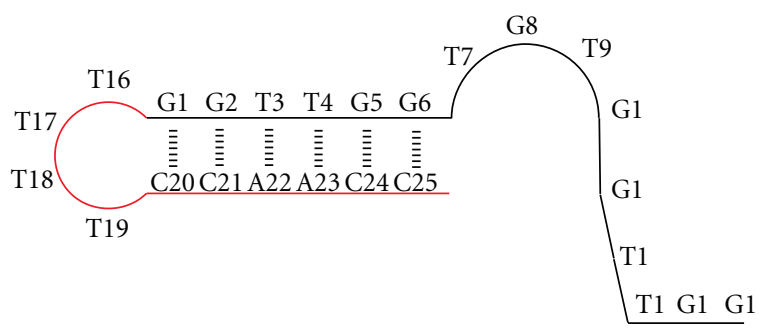

(c)

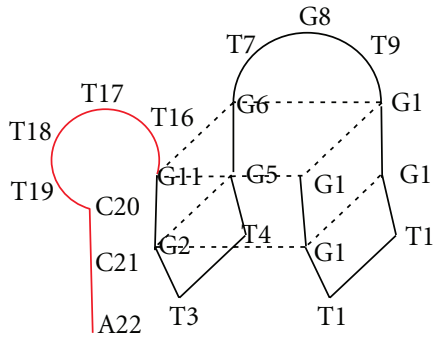

(b)

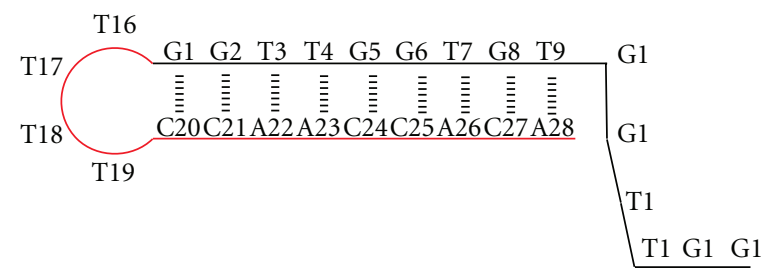

(d)

FIGURE 3: Schematic representation of the structure of several derivatives of thrombin-binding aptamers (TBAs) prepared in this study. TBA sequence is shown in black, and T4 loop with different sizes of the complementary sequences are shown in red. (a) Native TBA; (b) TBA-hairpin containing three overhanging complementary nucleotides (3-HP-TBA); (c) TBA-hairpin containing six overhanging complementary nucleotides (6-HP-TBA); (d) TBA-hairpin containing nine overhanging complementary nucleotides (9-HP-TBA). Between 3-6 complementary nucleotides are required to disrupt the intramolecular quadruplex to form an intramolecular duplex.

out at $\mathrm{pH} 7$ in buffer containing $10 \mathrm{mM}$ sodium cacodylate and $100 \mathrm{mM} \mathrm{KCl}$, which is predicted to stabilize Gquadruplexes structures. We did not observe a melting temperature at $295 \mathrm{~nm}$ for $5-\mathrm{O}^{6}-\mathrm{MeG}-\mathrm{TBA}$ or $6-\mathrm{O}^{6}-\mathrm{MeG}-$ TBA and the corresponding molecular beacons (see Figures S1-S4 in Supplementary Data Material available online at doi: 10.4061/2010/632041). The absence of this transition is consistent with the disruption of the quadruplex structure. These results contrast with the melting temperature of native TBA $\left(\operatorname{Tm} 48^{\circ} \mathrm{C}\right)$ and $\mathrm{MB}-\mathrm{TBA}\left(\operatorname{Tm} 46^{\circ} \mathrm{C}\right)$. Moreover, circular dicroism of methylated-TBA derivatives did not show the presence of the maximum at $295 \mathrm{~nm}$, which is characteristic of the antiparallel quadruplex of TBA (Figure 2 and Figure S5). These results confirmed that methylation of guanine in either of the two positions of the TBA sequence prevents the formation of the chair structure. This observation confirms our working hypothesis.

Given that the DNA repair activity exerted by hAGT is higher in double-stranded DNA than single-stranded DNA [39], we studied the stability and the quadruplex formation of elongated self-complementary TBA derivatives (see Table 1). We designed several TBA oligonucleotides elongated in their $3^{\prime}$ end with a subset of self-complementary sequences of diverse sizes. The purpose of these elongations was to check whether the extended sequences have the capacity to form a double strand helix of different lengths and strengths with themselves without disrupting the chairlike structure. For 6-HP-TBA and 9-HP-TBA, we found that the corresponding $\mathrm{Tm}$ at $260 \mathrm{~nm}$ were $63^{\circ} \mathrm{C}$ and $71.8^{\circ} \mathrm{C}$, respectively. This observation confirms our hypothesis of a double helix structure that increases in strength as the sequence length increases. However, we did not detect a melting temperature of these two sequences at $295 \mathrm{~nm}$. The absence of a transition at $295 \mathrm{~nm}$ is consistent with the absence of an antiparallel quadruplex structure. In contrast, 3-HP-TBA, corresponding to an overhang of only 3 nucleotides, gave a melting temperature of $46^{\circ} \mathrm{C}$ at $295 \mathrm{~nm}$, which is slightly but similar to that obtained for natural TBA. This result indicates that 3-HP-TBA forms an antiparallel quadruplex instead of a duplex because the overhang is too short to break the chair-like structure. Circular dichroism confirms the quadruplex structure of 3-HP-TBA and the absence of quadruplex structure in 6-HP-TBA and 9-HPTBA (Figure S6). Models of all these structures are shown in Figure 3.

3.3. HPLC Analysis of DNA Repair Activity of hAGT. In order to observe the efficiency of hAGT to remove alkyl groups from single-stranded oligonucleotides, we performed several assays to determine the optimal conditions of the reaction.

For this purpose, the full-length hAGT was first overexpressed and purified as described previously [36]. Increasing concentrations of the protein were incubated with double-stranded 5- $\mathrm{O}^{6}-\mathrm{MeG}$ and 6- $\mathrm{O}^{6}-\mathrm{MeG}$ TBA, annealed with its complementary sequence. Figure 4(a) shows the HPLC profile of the final product of the reaction with double-stranded $5-\mathrm{O}^{6}-\mathrm{MeG}-\mathrm{TBA}$. In order to separate the two strands of the TBA substrate (Figure 4(a) top right panel), HPLC analyses were done at $60^{\circ} \mathrm{C}$. After incubation with hAGT, we detected a peak with a shorter retention time, which corresponds to the restored TBA sequence caused by 


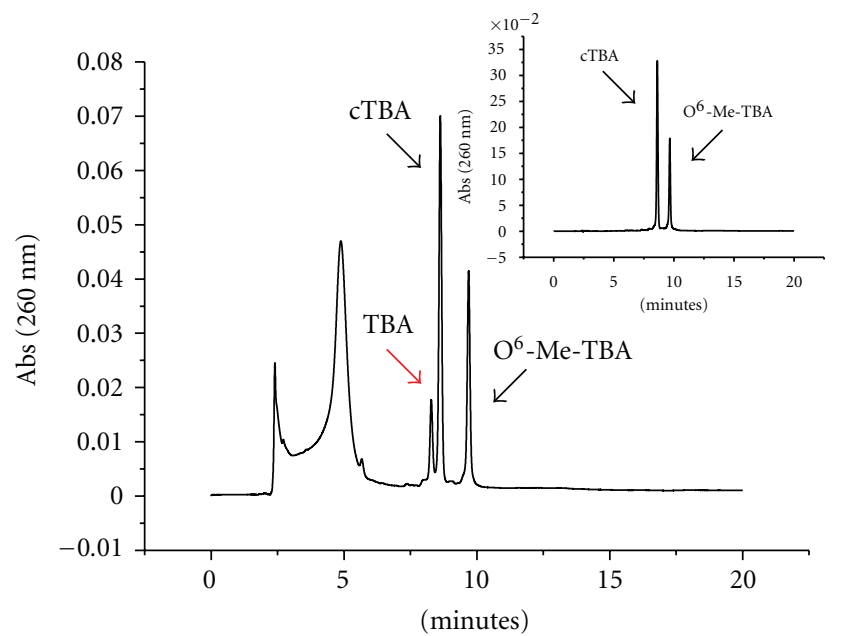

(a)

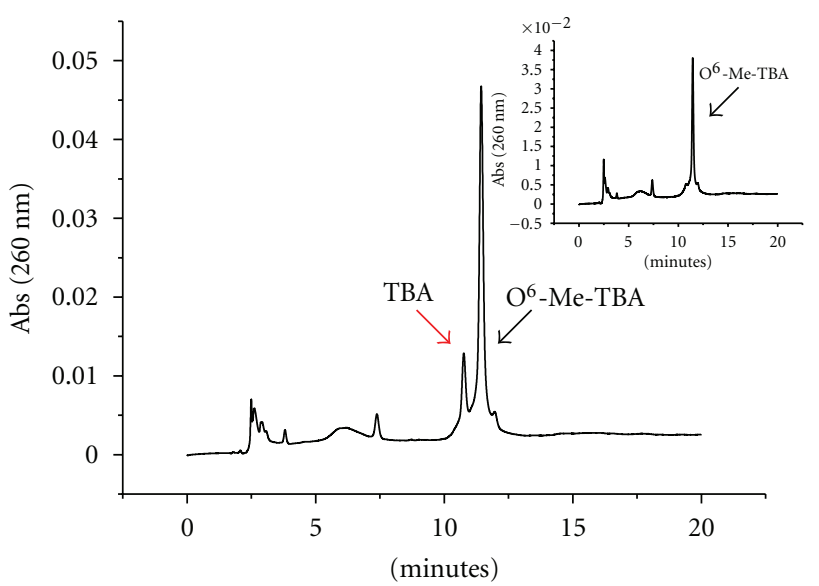

(b)

FIGURE 4: HPLC analysis of hAGT activity over double- and single-stranded TBA before and after incubation with hAGT. (a) Repair of double-stranded 5-O $\mathrm{O}^{6}-\mathrm{MeG}-\mathrm{TBA}$ by hAGT. The peak labelled as cTBA corresponds to the complementary sequence of 5-O ${ }^{6}-\mathrm{MeG}^{-} \mathrm{TBA}$. The top right panel shows HPLC chromatogram in absence of hAGT. The gradient was from $10 \%-40 \%$ acetonitrile for $20 \mathrm{~min}$ at $60^{\circ} \mathrm{C}$. (b) Repair of single- stranded 5-O $-\mathrm{MeG}-\mathrm{TBA}$ by hAGT. The inserted panel shows HPLC chromatogram in the absence of hAGT. Gradient used: $10 \%-40 \%$ acetonitrile, $20 \mathrm{~min}$ at room temperature.

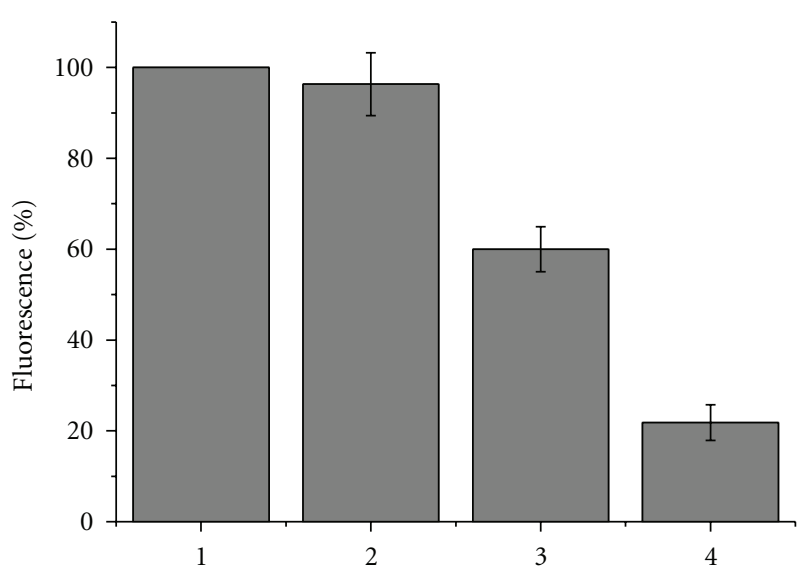

(a)

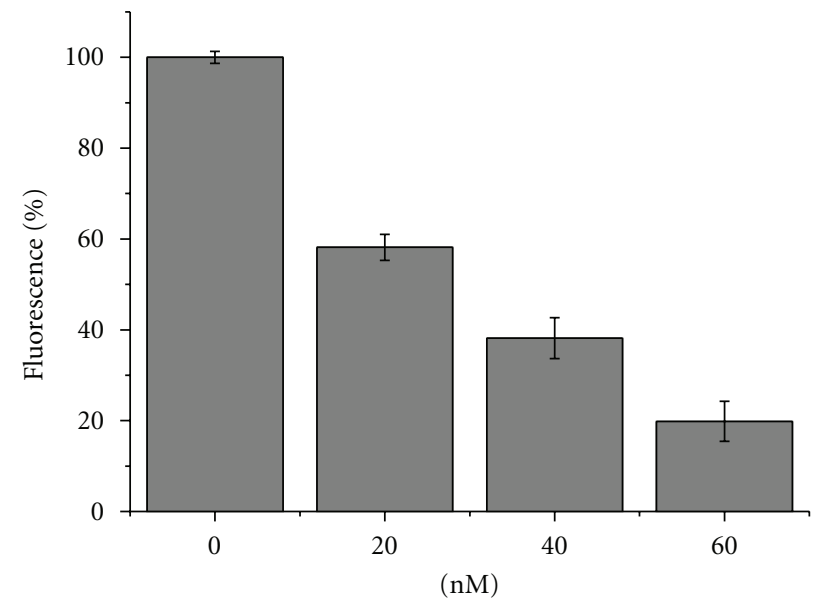

(b)

FIGURE 5: Fluorescence intensity of the real-time hAGT assay, measured at excitation and emission wavelengths of $485 \mathrm{~nm}$ and 535 , respectively. (a) Illustration of the different controls with $5 \mathrm{nM}$ MB-5-O 6 -MeG-TBA: (1) Positive control of $\mathrm{MB}^{-5}-\mathrm{O}^{6}-\mathrm{MeG}^{-T B A}$ in the absence of hAGT; (2) Intensity in presence of the inactive mutant hAGT-C145S; (3) Decrease in fluorescence when adding $40 \mathrm{nM}$ active hAGT; and (4) basal fluorescence of $5 \mathrm{nM}$ of MB-TBA. (b) Decrease in intensity caused by the activity of hAGT at a range of concentrations $(0,20,40$, and $60 \mathrm{nM})$, in all of them the basal fluorescence of MB-TBA was subtracted.

the removal of the methyl group. We obtained the same results when we used double-stranded $6-\mathrm{O}^{6}-\mathrm{MeG}-\mathrm{TBA}$ as a substrate (data not shown). As expected, hAGT activity was not affected by the position of the alkyl group within the sequence. We then tested hAGT activity over single-stranded methylated TBA in the previously optimized conditions and obtained similar results to those shown in Figure 4(b). The top right panel shows the HPLC chromatogram in the absence of hAGT. In this case, the HPLC analyses were performed at room temperature because the substrate was single-stranded TBA. Our results confirmed that hAGT has the capacity to remove methyl groups from single- or doublestranded TBA with the same efficacy. Therefore, we selected single-stranded TBA as substrate for the development of our fluorescence assay.

3.4. Fluorescence hAGT Activity Assay. On the basis of the results obtained in the melting temperature and the HPLC experiments, we tested the effectiveness of our proposed model to the DNA repair activity of hAGT by means of fluorescence. First of all, we determined the minimum amount of TBA required to achieve a detectable and reliable 
difference in intensity compared to the background. As expected, the negative control natural TBA quadruplex gave low background fluorescence, because of the proximity of the fluorophore and the quencher groups in the chair-like structure (Figure 5(a)). Although the fluorescence of MBTBA was low, this fluorescence was subtracted from the fluorescence value in each experiment. The concentration of $5 \mathrm{nM}$ of fluorescently labelled $\mathrm{MB}-\mathrm{O}^{6}-\mathrm{MeG}-\mathrm{TBA}$ was considered the optimal concentration as the fluorescence signal was intense and only a small amount of hAGT protein was required to achieve a substantial decrease in fluorescence in 20-40 min. In the optimal conditions, the presence of hAGT produced a remarkable decrease in fluorescence intensity, caused by the demethylation of the $\mathrm{O}^{6}$ position of guanines, thereby allowing the TBA to form its typical quadruplex structure, which brings together the fluorophore and the quencher groups, as occurred in the negative control. The rate of decrease in fluorescence intensity correlated directly with the amount of hAGT in the reaction mixture (Figure 5(b)). Moreover, the inactive mutant hAGT-C145S did not exhibit any decrease in fluorescence (Figure 5(a)). This result was expected because of the inability of this mutated protein to repair the modified TBA. Figure 5(b) shows the fluorescence intensities for the real time hAGT assay. All these observations are consistent with the hypothesis and design of our FRET method.

\section{Conclusion}

Although radioactivity has been widely used in the search of potential inhibitors of hAGT $[23,24]$, this technique does not allow real-time data acquisition and, in addition, requires radioactive materials. Here, we developed a sensitive fluorescence method that allows the quantification of hAGT activity in a single step and in a straightforward manner. Although another fluorescence method has already been developed for this purpose [25], it requires the addition of a restriction enzyme, followed by the addition of an exonuclease after the hAGT activity reaction. Consequently, although it is a real-time assay, a three-step reaction is required before observing an increase in fluorescence. In contrast, in our assay, a change in fluorescence is detected in a single step (homogeneous), and this method does not depend on the activity of two additional enzymes.

Our assay is based on the detection of conformational changes of TBA in the presence or absence of $\mathrm{O}^{6}$ methylguanines in its structure. The quadruplex structure of TBA is disrupted when a central guanine is replaced by an $\mathrm{O}^{6}$-methylguanine. Fluorophore groups can be added to the modified sequence in order to detect the conformational changes by fluorescence. The variation in fluorescence can be quantified as a direct measurement of hAGT activity. In addition, this technique requires lower amounts of substrate and does not call for the use of radioactive materials. Furthermore, this method can be easily transferred to a high throughput experiment for the evaluation of small molecules as potential hAGT inhibitors [36]. Research in this direction is currently underway in the laboratory.

\section{Abbreviations}

BME: 2-mercaptoethanol

Dabsyl: 3-(N-4' -sulfonyl-4-(dimethylamino)azobenzene)-3-aminopropyl

dmf: Dimethylformamidino group

DTT: Dithiothreitol

EDTA: Ethylenediaminetetraacetic acid

FAM: Fluoresceine

AGT: $\quad O^{6}$-alkylguanine-DNA alkyltransferase

hAGT: Human AGT

HPLC: High performance liquid chromatography

IPTG: $\quad$ Isopropyl $\beta$-D-1-thiogalactopyranoside

MB: $\quad$ Molecular Beacon

$\mathrm{O}^{6}$-MeG: $\mathrm{O}^{6}$-methylguanine

TBA: Thrombin-binding aptamer

cTBA: Complementary TBA

TEAA: Triethylammonium acetate

TFA: Trifluoroacetic acid

Tris: $\quad$ Tris(hydroxymethyl)aminomethane

Tm: $\quad$ Melting temperature

UV: Ultraviolet.

\section{Acknowledgments}

This work was supported by the Fondo de Investigaciones Sanitarias (Grant PI06/1250), by the Dirección General de Investigación Científica y Técnica (Grant BFU200763287, CTQ2010-20541), the Generalitat de Catalunya (2009/SGR/208), the COST project (G4-net, MP0802), the Instituto de Salud Carlos III (CIBER-BNN, CB06_01_0019), and a SNS Miguel Servet contract from the Instituto de Salud Carlos III. The authors thank Tanya Yates for editing the paper and the reviewer for the detailed revision of the paper. This work is dedicated to the memory of Ángel Ramírez Ortiz who was a great mentor, colleague, and friend.

\section{References}

[1] M. R. Middleton and G. P. Margison, "Improvement of chemotherapy efficacy by inactivation of a DNA-repair pathway," Lancet Oncology, vol. 4, no. 1, pp. 37-44, 2003.

[2] A. Sabharwal and M. R. Middleton, "Exploiting the role of $\mathrm{O}^{6}$ methylguanine-DNA-methyltransferase (MGMT) in cancer therapy," Current Opinion in Pharmacology, vol. 6, no. 4, pp. 355-363, 2006.

[3] A. E. Pegg and B. Singer, "Is $\mathrm{O}^{6}$-alkylguanine necessary for initiation of carcinogenesis by alkylating agents?" Cancer Investigation, vol. 2, p. 18, 1984.

[4] R. Saffhill, G. P. Margison, and P. J. O’Connor, "Mechanisms of carcinogenesis induced by alkylating agents," Biochimica et Biophysica Acta, vol. 823, no. 2, pp. 111-145, 1985.

[5] B. Singer, "O-Alkyl pyrimidines in mutagenesis and carcinogenesis: occurrence and significance," Cancer Research, vol. 46, no. 10 , pp. 4879-4885, 1986.

[6] K. A. Jaeckle, H. J. Eyre, J. J. Townsend et al., "Correlation of tumor $\mathrm{O}^{6}$ methylguanine-DNA methyltransferase levels with survival of malignant astrocytoma patients treated with bischloroethylnitrosourea: a Southwest Oncology Group study," Journal of Clinical Oncology, vol. 16, no. 10, pp. 3310-3315, 1998. 
[7] M. Belanich, M. Pastor, T. Randall et al., "Retrospective study of the correlation between the DNA repair protein alkyltransferase and survival of brain tumor patients treated with carmustine," Cancer Research, vol. 56, no. 4, pp. 783-788, 1996.

[8] R. S. Foote, S. Mitra, and B. C. Pal, "Demethylation of $\mathrm{O}^{6}$-methylguanine synthetic DNA polymer by an inducible activity in Escherichia coli," Biochemical and Biophysical Research Communications, vol. 97, no. 2, pp. 654-659, 1980.

[9] A. E. Pegg, "Mammalian $\mathrm{O}^{6}$-alkylguanine-DNA alkyltransferase: regulation and importance in response to alkylating carcinogenic and therapeutic agents," Cancer Research, vol. 50, no. 19, pp. 6119-6129, 1990.

[10] W. P. Tong, M. C. Kirk, and D. B. Ludlum, "Formation of the cross-link 1-[N3-deoxycytidyl],2-[N1-deoxyguanosinyl] ethane in DNA treated with N,N'-bis(2-chloroethyl)N-nitrosourea," Cancer Research, vol. 42, no. 8, pp. 3102-3105, 1982.

[11] L. Yan, J. R. Donze, and L. Liu, "Inactivated MGMT by $\mathrm{O}^{6}$ benzylguanine is associated with prolonged $\mathrm{G} 2 / \mathrm{M}$ arrest in cancer cells treated with BCNU," Oncogene, vol. 24, no. 13, pp. 2175-2183, 2005.

[12] T. P. Brent, P. J. Houghton, and J. A. Houghton, " $\mathrm{O}^{6}$ alkylguanine-DNA alkyltransferase activity correlates with the therapeutic response of human rhabdomyosarcoma xenografts to 1-(2-chloroethyl)-3-(trans-4-methylcyclohexyl)-1-nitrosourea," Proceedings of the National Academy of Sciences of the United States of America, vol. 82, no. 9, pp. 29852989, 1985.

[13] G. Tagliabue, L. Citti, G. Massazza, G. Damia, R. Giavazzi, and M. D'Incalci, "Tumour levels of $\mathrm{O}^{6}$-alkylguanineDNA-alkyltransferase and sensitivity to BCNU of human xenografts," Anticancer Research, vol. 12, no. 6B, pp. 21232125, 1992.

[14] R. Pepponi, G. Marra, M. P. Fuggetta et al., "The effect of $\mathrm{O}^{6}$-alkylguanine-DNA alkyltransferase and mismatch repair activities on the sensitivity of human melanoma cells to temozolomide, 1,3-bis(2-chloroethyl)1-nitrosourea, and cisplatin," Journal of Pharmacology and Experimental Therapeutics, vol. 304, no. 2, pp. 661-668, 2003.

[15] S. L. Gerson, "Clinical relevance of MGMT in the treatment of cancer," Journal of Clinical Oncology, vol. 20, no. 9, pp. 23882399, 2002.

[16] G. P. Margison, A. C. Povey, B. Kaina, and M. F. Santibáñez Koref, "Variability and regulation of $\mathrm{O}^{6}$-alkylguanine-DNA alkyltransferase," Carcinogenesis, vol. 24, no. 4, pp. 625-635, 2003.

[17] S. L. Gerson, "MGMT: its role in cancer aetiology and cancer therapeutics," Nature Reviews Cancer, vol. 4, no. 4, pp. 296307, 2004.

[18] M. E. Hegi, A.-C. Diserens, T. Gorlia et al., "MGMT gene silencing and benefit from temozolomide in glioblastoma," The New England Journal of Medicine, vol. 352, no. 10, pp. 9971003, 2005.

[19] M. Esteller, J. Garcia-Foncillas, E. Andion et al., "Inactivation of the DNA-repair gene MGMT and the clinical response of gliomas to alkylating agents," The New England Journal of Medicine, vol. 343, no. 19, pp. 1350-1354, 2000.

[20] A. E. Pegg, K. Swenn, M.-Y. Chae, M. E. Dolan, and R. C. Moschel, "Increased killing of prostate, breast, colon, and lung tumor cells by the combination of inactivators of $\mathrm{O}^{6}$-alkylguanine-DNA alkyltransferase and N,N'-bis(2chloroethyl)-N-nitrosourea," Biochemical Pharmacology, vol. 50, no. 8, pp. 1141-1148, 1995.
[21] K. S. Srivenugopal, X.-H. Yuan, H. S. Friedman, and F. Ali-Osman, "Ubiquitination-dependent proteolysis of $\mathrm{O}^{6}$ methylguanine-DNA methyltransferase in human and murine tumor cells following inactivation with $\mathrm{O}^{6}$-benzylguanine or 1,3-bis(2-chloroethyl)-1-nitrosourea," Biochemistry, vol. 35, no. 4, pp. 1328-1334, 1996.

[22] M. Xu-Welliver and A. E. Pegg, "Degradation of the alkylated form of the DNA repair protein, $\mathrm{O}^{6}$-alkylguanine-DNA alkyltransferase," Carcinogenesis, vol. 23, no. 5, pp. 823-830, 2002.

[23] B. D. Wilson, M. Strauss, B. J. Stickells, E. G. Hoal-van Helden, and P. D. Van Helden, "An assay for $\mathrm{O}^{6}$-alkylguanine-DNA alkyltransferase based on restriction endonuclease inhibition and magnetic bead separation of products," Carcinogenesis, vol. 15, no. 10, pp. 2143-2148, 1994.

[24] M. E. Dolan, D. Schicchitiano, and A. E. Pegg, "Use of oligodeoxynucleotides containing $\mathrm{O}^{6}$-alkylguanine for the assay of $\mathrm{O}^{6}$-alkylguanine-DNA-alkyltransferase activity," Cancer Research, vol. 48, no. 5, pp. 1184-1188, 1988.

[25] A. M. Moser, M. Patel, H. Yoo, F. M. Balis, and M. E. Hawkins, "Real-time fluorescence assay for $\mathrm{O}^{6}$-alkylguanineDNA alkyltransferase," Analytical Biochemistry, vol. 281, no. 2, pp. 216-222, 2000.

[26] R. S. Wu, S. Hurst-Calderone, and K. W. Kohn, "Measurement of $\mathrm{O}^{6}$-alkylguanine-DNA alkyltransferase activity in human cells and tumor tissues by restriction endonuclease inhibition," Cancer Research, vol. 47, no. 23, pp. 6229-6235, 1987.

[27] J. L. Huppert, "Four-stranded nucleic acids: structure, function and targeting of G-quadruplexes," Chemical Society Reviews, vol. 37, no. 7, pp. 1375-1384, 2008.

[28] S. Neidle, "The structures of quadruplex nucleic acids and their drug complexes," Current Opinion in Structural Biology, vol. 19, no. 3, pp. 239-250, 2009.

[29] N. V. Hud, F. W. Smith, F. A. L. Anet, and J. Feigon, "The selectivity for $\mathrm{K}^{+}$versus $\mathrm{Na}^{+}$in DNA quadruplexes is dominated by relative free energies of hydration: a thermodynamic analysis by 1 H NMR," Biochemistry, vol. 35, no. 48, pp. 15383-15390, 1996.

[30] S. Burge, G. N. Parkinson, P. Hazel, A. K. Todd, and S. Neidle, "Quadruplex DNA: sequence, topology and structure," Nucleic Acids Research, vol. 34, no. 19, pp. 5402-5415, 2006.

[31] S. W. Blume, V. Guarcello, W. Zacharias, and D. M. Miller, "Divalent transition metal cations counteract potassiuminduced quadruplex assembly of oligo(dG) sequences," Nucleic Acids Research, vol. 25, no. 3, pp. 617-625, 1997.

[32] A. G. Petrovic and P. L. Polavarapu, "Quadruplex structure of polyriboinosinic acid: dependence on alkali metal ion concentration, $\mathrm{pH}$ and temperature," Journal of Physical Chemistry B, vol. 112, no. 7, pp. 2255-2260, 2008.

[33] C. S. Mekmaysy, L. Petraccone, N. C. Garbett et al., "Effect of $\mathrm{O}^{6}$-methylguanine on the stability of G-quadruplex DNA," Journal of the American Chemical Society, vol. 130, no. 21, pp. 6710-6711, 2008.

[34] R. F. Macaya, P. Schultze, F. W. Smith, J. A. Roe, and J. Feigon, "Thrombin-binding DNA aptamer forms a unimolecular quadruplex structure in solution," Proceedings of the National Academy of Sciences of the United States of America, vol. 90, no. 8, pp. 3745-3749, 1993.

[35] O. S. Bhanot and A. Ray, "The in vivo mutagenic frequency and specificity of $\mathrm{O}^{6}$-methylguanine in $\varphi \mathrm{X} 174$ replicative form DNA," Proceedings of the National Academy of Sciences of the United States of America, vol. 83, no. 19, pp. 7348-7352, 1986. 
[36] F. M. Ruiz, R. Gil-Redondo, A. Morreale, Á. R. Ortiz, C. Fábrega, and J. Bravo, "Structure-based discovery of novel non-nucleosidic DNA alkyltransferase inhibitors: virtual screening and in vitro and in vivo activities," Journal of Chemical Information and Modeling, vol. 48, no. 4, pp. 844854, 2008.

[37] M. H. Caruthers, A. D. Barone, S. L. Beaucage et al., "Chemical synthesis of deoxyoligonucleotides by the phosphoramidite method," Methods in Enzymology, vol. 154, pp. 287-313, 1987.

[38] H. Vu, C. McCollum, C. Lotys, and A. Andrus, "New reagents and solid support for automated oligonucleotide synthesis," Nucleic Acids Symposium Series, no. 22, pp. 63-64, 1990.

[39] J. J. Rasimas, A. E. Pegg, and M. G. Fried, "DNA-binding mechanism of $\mathrm{O}^{6}$-alkylguanine-DNA alkyltransferase: effects of protein and DNA alkylation on complex stability," Journal of Biological Chemistry, vol. 278, no. 10, pp. 7973-7980, 2003. 

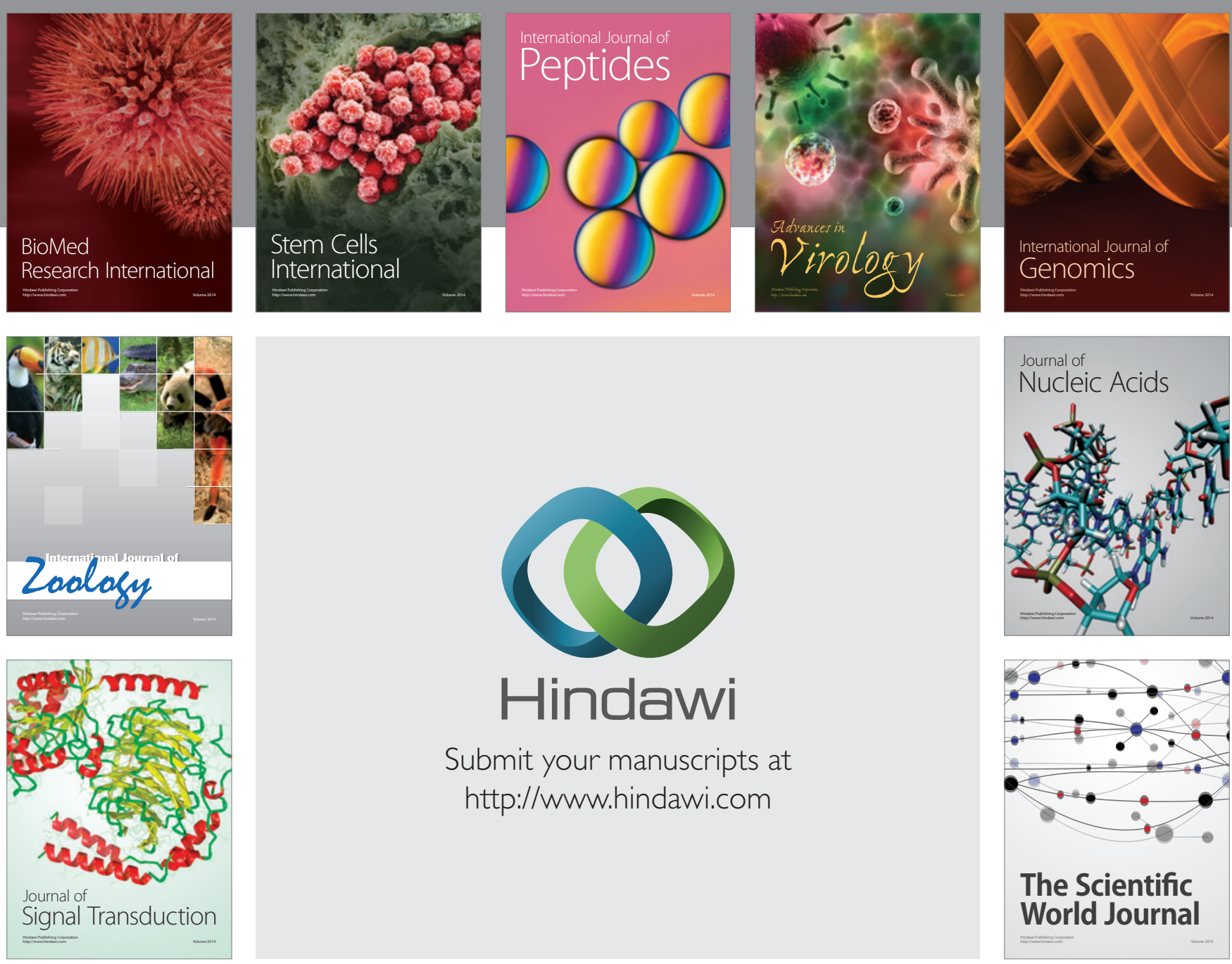

Submit your manuscripts at

http://www.hindawi.com
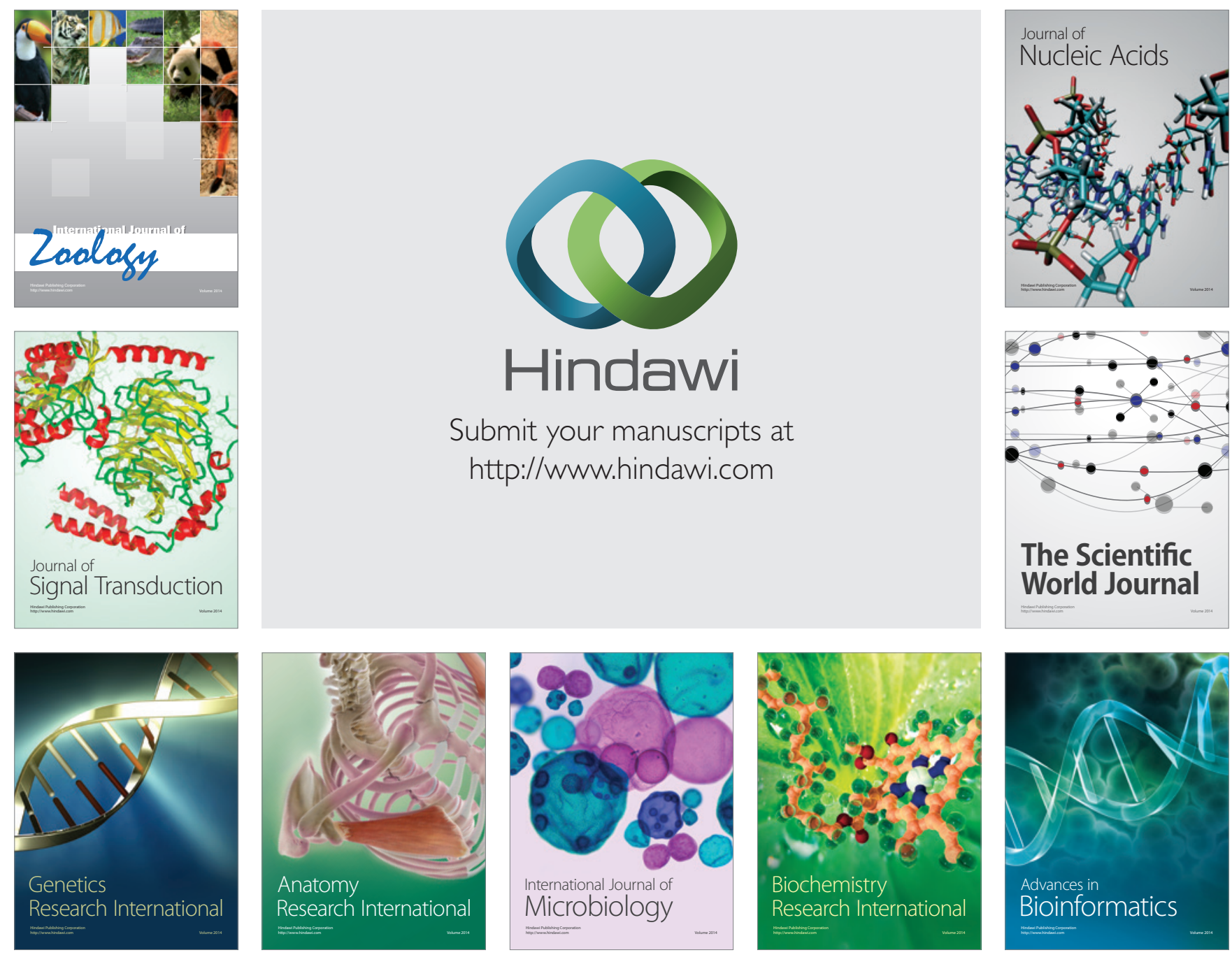

The Scientific World Journal
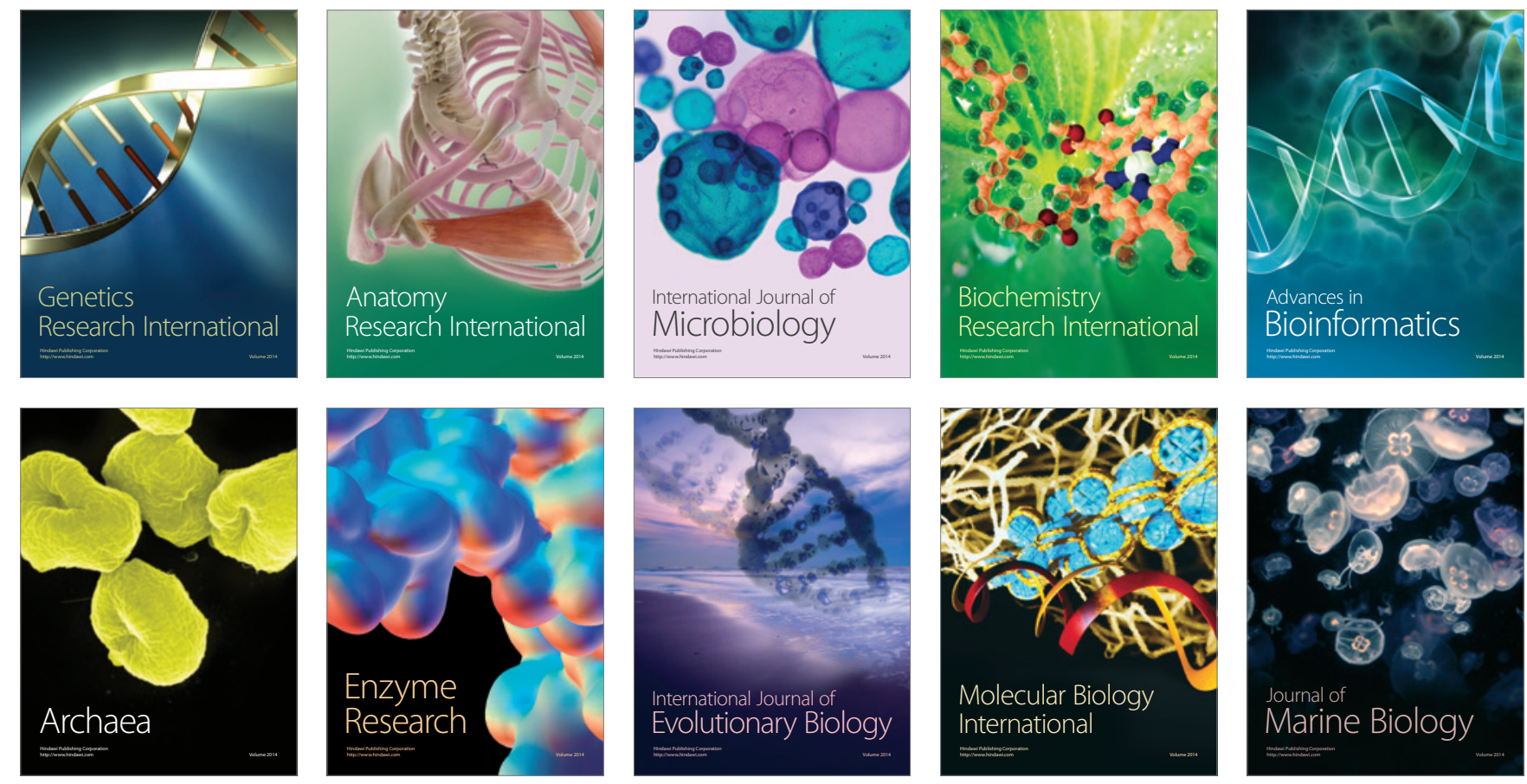